Supporting Information (SI) for

\title{
Nanoporous Carbon Derived from Core-Shells@Sheets through Template-Activation Method for Effective Adsorption of Dyes
}

\author{
Yanyan Liu, ${ }^{\dagger}$ Shimin Wang, ${ }^{\ddagger}$ Congcong Xing, ${ }^{\dagger}$ Hang Du ${ }^{\dagger}$ Chenxia $\mathrm{Du}^{*}{ }^{* \dagger}$ and Baojun $\mathrm{Li}^{*},{ }^{*}$ \\ ${ }^{\dagger}$ College of Chemistry and Molecular Engineering, Zhengzhou University, 100 Science Road, Zhengzhou 450001, \\ P R China \\ * College of Material and Chemistry Engineering, Henan University of Engineering, 1 Xianghe Road, Zhengzhou \\ 451191, P R China \\ * Corresponding Author. E-mail: dcx@zzu.edu.cn (C.X. Du) and lbjfcl@zzu.edu.cn (B.J. Li).
}



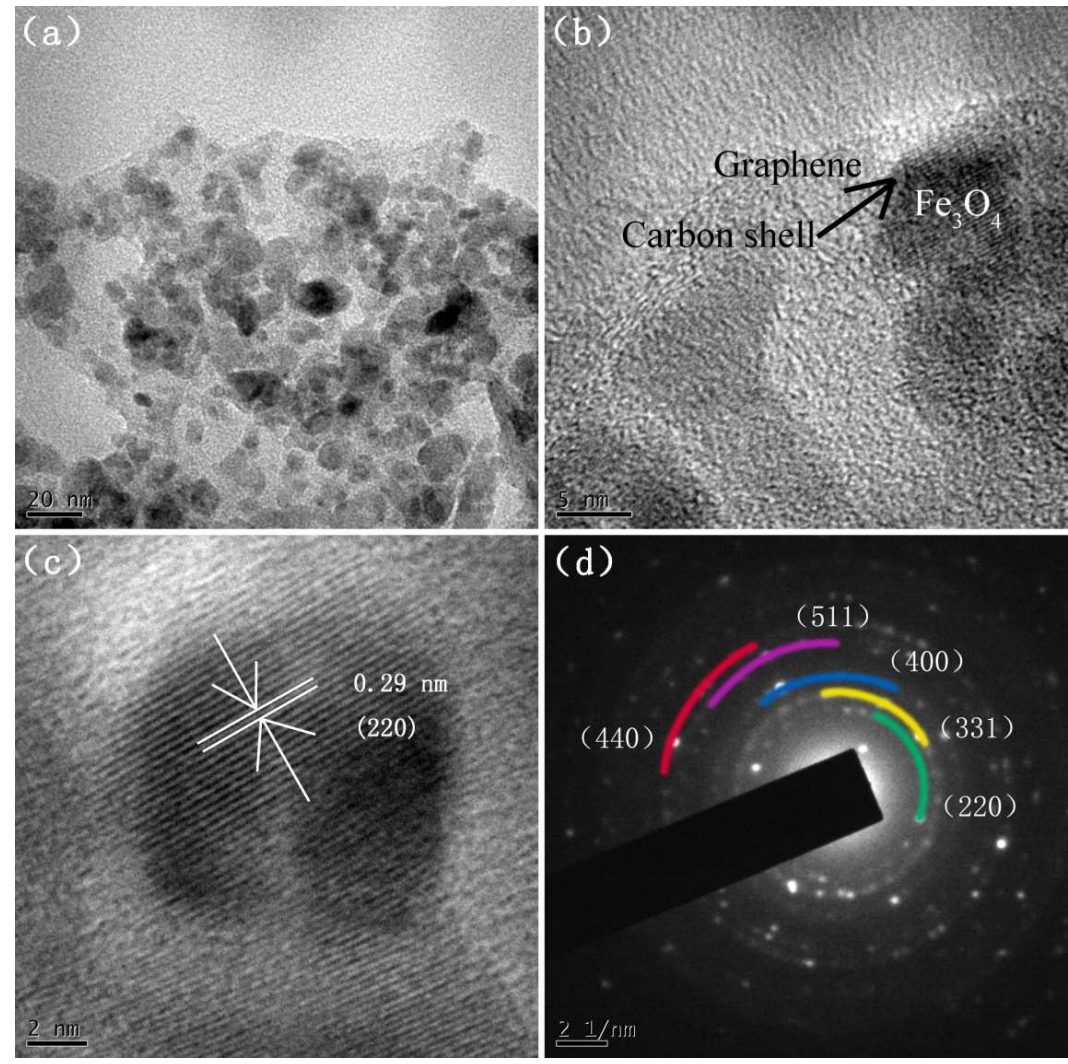

Figure S1. (a, b) TEM, (c) HRTEM images, and (d) SAED pattern of FCG.

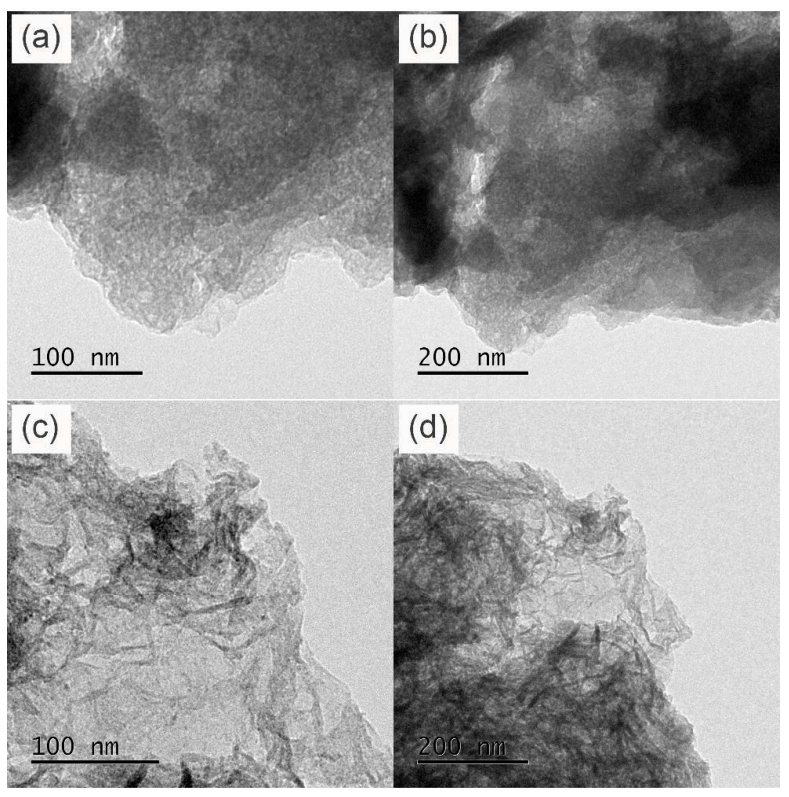

Figure S2. TEM images of (a, b) C@rGO-550, and (c, d) C@rGO-750. 


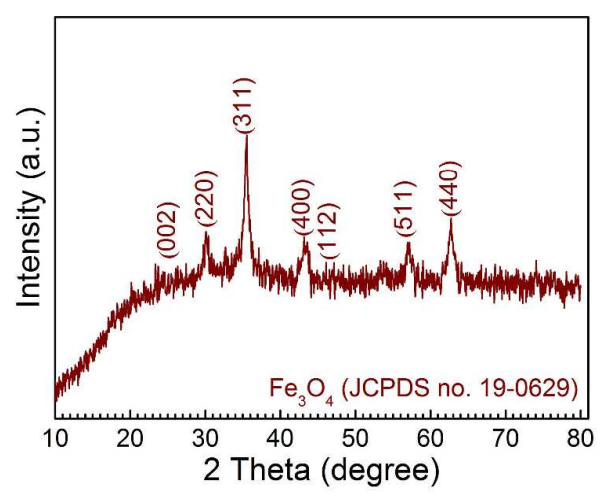

Figure S3. XRD pattern of FCG.
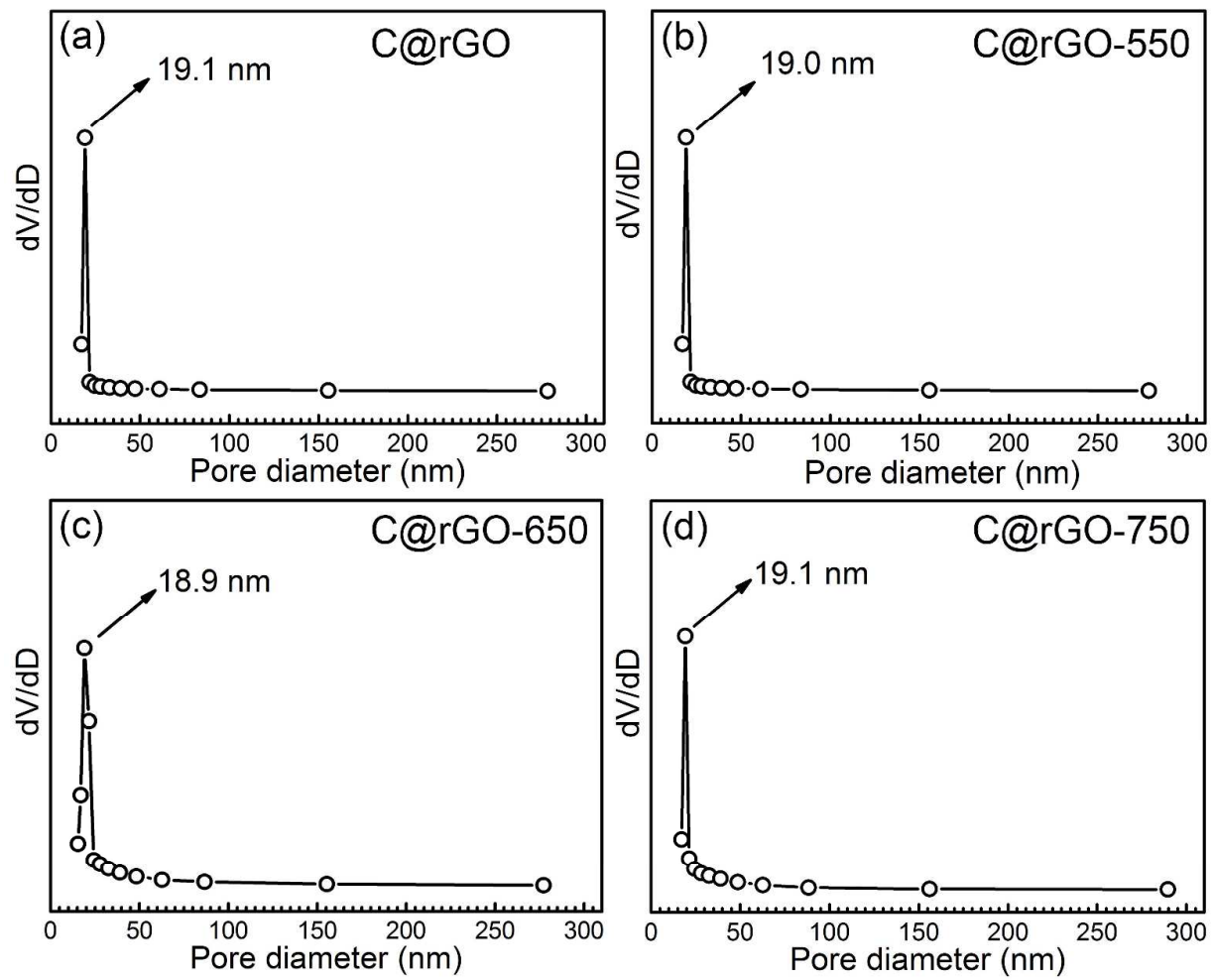

Figure S4. The pore diameter distribution of (a) C@rGO, (b) C@rGO-550, (c) C@rGO-650 and, (d) C@rGO-750. 


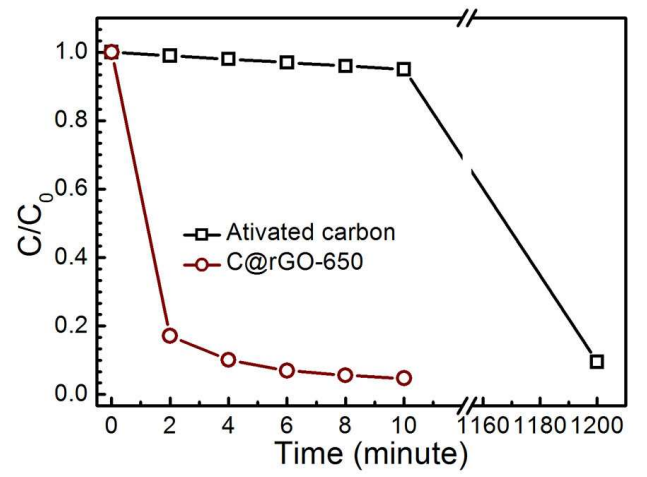

Figure S5. The $\mathrm{C} / \mathrm{C}_{0}$ versus time plots for adsorption of $\mathrm{Rh}-\mathrm{B}$ solution $(125 \mathrm{~mL})$ with different absorbent $(25 \mathrm{mg})$.

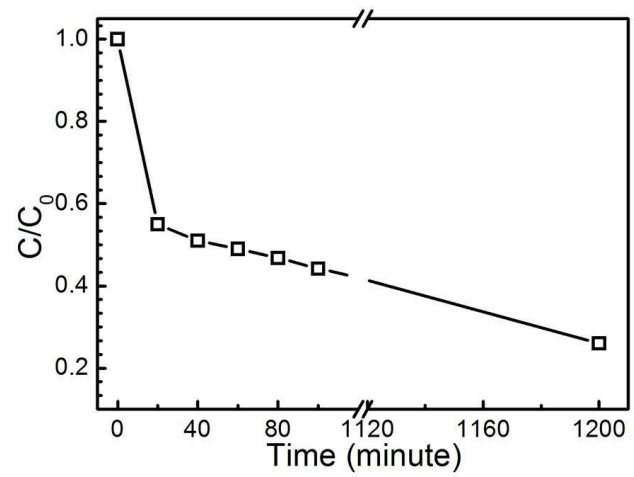

Figure S6. The $\mathrm{C} / \mathrm{C}_{0}$ versus time plots for adsorption of Rh-B solution $(300 \mathrm{~mL})$ with $\mathrm{C} @ \mathrm{rGO}-650(15 \mathrm{mg})$. 